\title{
Correlates of comorbid anxiety and externalizing disorders in childhood obsessive compulsive disorder
}

\author{
Audra K. Langley $\cdot$ Adam B. Lewin • \\ R. Lindsey Bergman · Joyce C. Lee • \\ John Piacentini
}

Received: 23 December 2008/Accepted: 3 March 2010/Published online: 28 March 2010

(C) The Author(s) 2010. This article is published with open access at Springerlink.com

\begin{abstract}
The present study examines the influence of diagnostic comorbidity on the demographic, psychiatric, and functional status of youth with a primary diagnosis of obsessive compulsive disorder (OCD). Two hundred and fifteen children (ages 5-17) referred to a university-based OCD specialty clinic were compared based on DSM-IV diagnostic profile: OCD without comorbid anxiety or externalizing disorder, OCD plus anxiety disorder, and OCD plus externalizing disorder. No age or gender differences were found across groups. Higher OCD severity was found for the OCD + ANX group, while the OCD + EXT group reported greater functional impairment than the other two groups. Lower family cohesion was reported by the OCD + EXT group compared to the OCD group and the OCD + ANX group reported higher family conflict compared to the OCD + EXT group. The $\mathrm{OCD}+\mathrm{ANX}$ group had significantly lower rates of tic disorders while rates of depressive disorders did not differ among the three groups. The presence of comorbid anxiety and externalizing psychopathology are associated with greater symptom severity and functional and family impairment and underscores the importance of a better understanding of the relationship of OCD characteristics and associated disorders. Results and clinical implications are further discussed.
\end{abstract}

A. K. Langley $(\bowtie) \cdot$ A. B. Lewin · R. L. Bergman ·

J. C. Lee $\cdot$ J. Piacentini

Division of Child and Adolescent Psychiatry, UCLA Semel Institute for Neuroscience and Human Behavior, 300 UCLA Medical Plaza, Suite 1315, Los Angeles, CA 90095, USA

e-mail: alangley@mednet.ucla.edu

A. B. Lewin

Rothman Center for Pediatric Neuropsychiatry, University of South Florida School of Medicine, St. Petersburg, FL, USA
Keywords Child · Adolescent · OCD · Comorbidity · Anxiety $\cdot$ Externalizing

\section{Introduction}

Obsessive compulsive disorder (OCD) is a relatively common disorder with a lifetime prevalence of $1-3 \%$ in children and adolescents [8, 54]. Childhood OCD typically runs a chronic and often disabling course [10, 21, 45] and can cause pervasive impairments in social, academic, and familial functioning $[23,37]$. Over half of adults with OCD report symptoms beginning during childhood or adolescence [38] and evidence suggests that pediatric OCD may predict adult morbidity [26]. OCD is a highly comorbid disorder in childhood with up to $80 \%$ of affected youngsters meeting diagnostic criteria for another mental health disorder, most commonly another anxiety disorder (26$75 \%)$, depressive disorder (25-62\%), externalizing disorder [18-50\%; i.e., attention deficit disorder, oppositional defiant disorder (ODD), conduct disorder (CD)], or tic disorder (15-30\%) [13, 15, 17, 24, 39, 40, 49].

Given the heterogeneous nature of OCD in childhood, recent research has sought to identify distinct clinical subgroups of OCD-diagnosed youth. The identification of distinct subgroups, including those based on comorbidity, offers potential utility in understanding variations in age of OCD-onset, symptom expression and course, family/genetics, [11, 17, 32, 41, 49], and treatment response [29, 46].

Only a few studies examining the correlates of comorbidity in children and adults with OCD have been published; unfortunately, this area remains largely understudied. Geller et al. [12] compared child behavior checklist (CBCL) syndrome, competence, and composite scores in children with (1) OCD with ADHD, (2) OCD without ADHD, (3) ADHD without $\mathrm{OCD}$, (4) controls from a general pediatrics clinic. 
Results indicated that youth with OCD + ADHD had higher $T$ scores on social problems, attention problems, and delinquent and aggressive behaviors, lower school and social competence scores, and higher externalizing and total composite $T$ scores as compared to subjects with OCD without ADHD. Similarly, Hanna et al. [15] found youth with OCD and a comorbid disruptive behavior disorder to have higher internalizing, externalizing, and total CBCL scores as compared to youth with OCD and no comorbid disruptive behavior disorder. Finally, Ivarsson et al. [17] concluded that among children and adolescents with OCD the burden of co-morbidity is quite high, finding elevated levels of problems with depression/anxiety, aggressive behavior, thought problems and attention problems on the CBCL. Comorbidities explained from 25 to $50 \%$ scores of the CBCL sub-syndrome scales.

While studies have shown rates of comorbid depressive disorder in childhood OCD to be low [30, 36, 51], the presence of clinically elevated depressive symptoms may be as high as $20 \%$ among youth with OCD [34]. Also, depression has been noted to increase steadily over the course of adolescence and adulthood [1], suggesting that depression may emerge secondary to OCD for some individuals [4]. While this finding is difficult to interpret given the increased risk for depression, in general, as children get older, comparing depression across comorbid groups of youth with OCD may yield useful mediating information.

More work has been focused on OCD with and without comorbid tic disorder. Hanna and colleagues [14] found that OCD patients without a tic disorder were more likely to report compulsive behaviors (specifically ordering, hoarding, and washing/cleaning compulsions) than patients with a tic disorder. Storch et al. [47] found that OCD patients without a tic disorder had significantly more contamination obsessions, sexual obsessions, and counting compulsions than youth with comorbid tics. Among adults, Tukel et al. [50] found that OCD with any comorbidity resulted in greater severity of both obsessions and compulsions.

Two studies have assessed the impact of psychiatric comorbidity on treatment response in youth with OCD. Storch et al. [46] found that the presence of comorbidity, particularly disruptive behavior disorder, depressive disorder, and attention deficit hyperactivity disorder, but not tic disorder, negatively impacted response to cognitivebehavioral therapy (CBT). This is consistent with Abramowitz and Foa [3] who reported worse response to exposure plus response prevention (ERP) in adults with OCD and depression compared to OCD only. March and colleagues [27] found that the presence of a tic disorder did not impact response to CBT, but did negatively impacted response to sertraline.
Unfortunately, although very common, the impact of the presence of comorbid anxiety disorders on OCD presentation remains unstudied in children and adolescents. However, Abramowitz and Foa [2] found that OCD with comorbid GAD was associated with higher rates of indecisiveness and pathological responsibility among adults studied. In children with non-OCD anxiety disorders, Franco et al. [9] found the presence of comorbid psychopathology was associated with more functional impairments and heightened clinical symptomatology.

\section{Study aims}

The primary goal of the current study was to examine the influence of diagnostic comorbidity on the demographic, psychiatric, and functional status of children and adolescents with a primary diagnosis of OCD. To this end, three study groups were formed based on DSM-IV diagnostic profile: OCD without comorbid anxiety or externalizing disorder (OCD), OCD with another anxiety disorder but not externalizing disorder (OCD + ANX), and OCD with an externalizing disorder (e.g., ADHD, ODD, or CD) but not anxiety disorder (OCD + EXT). These divisions are consistent with prior evaluations of comorbidity patterns in children with anxiety $[9,48]$.

Based on previous research, we hypothesized that the study groups would not differ in terms of demographic status (e.g., [9]). However, we predicted that both comorbidity groups would be associated with higher levels of psychiatric symptoms, and greater functional impairment and family dysfunction. We also expected that the OCD + ANX group would have more depressive symptoms, and a lower prevalence of comorbid tic disorder, than the OCD and OCD + EXT groups.

\section{Method}

Participants

Participants included a consecutive series of 215 children (57\% male) and their primary parent who were sequentially evaluated following referral to a university-based mental health clinic specializing in the diagnosis and treatment of childhood OCD. Children ranged in age from 5 to 17 years (mean 11.8 years, SD 3.0). Eighty-one percent of the participants identified themselves as Caucasian, with $10 \%$ of the participants identifying as multiracial, $5 \%$ as Latino, $2 \%$ as Asian-American, and 2\% as African-American. All participants in the sample met criteria for a primary DSMIV diagnosis of OCD. Thirty-two percent of the participants were on medication at baseline. 
Measures

Anxiety disorders interview schedule for children, version $I V$

The anxiety disorders interview schedule for children, version IV (ADIS-IV) [42] is a semi-structured interview that assesses the major DSM-IV anxiety, mood, and externalizing disorders experienced by school-aged children and adolescents. This interview has demonstrated favorable psychometric properties [43, 53]. In addition to generating DSM-IV diagnoses, interviewers also assigned a clinical severity rating (CSR), based on an 8-point scale ( $0=$ not at all, $4=$ some, $8=$ very, very much $)$, for each assigned diagnosis [42]. The ADIS-IV was supplemented with the tic disorders diagnostic section from the Kiddie Schedule for Affective Disorders and Schizophrenia (KSADS-PL) [18] given that the version of the ADIS-IV available at study commencement did not include an assessment of tic disorders.

\section{Multidimensional anxiety scale for children}

The multidimensional anxiety scale for children (MASC) [28] is a standardized 39-item child self-report measure of anxiety yielding four scale scores and a total score. Each item is rated on a four-point Likert-type response scale ranging from "Never true about me" (0) to "Often true about me" (3). Higher scores suggest more symptoms of anxiety. The four scales were empirically derived through principal components analysis and include: social anxiety (9 items), separation anxiety/panic (9 items), harm avoidance (9 items), and physical symptoms (12 items). Cronbach's alpha [7] for the total MASC score was 0.83 in the present sample. The MASC total score was used in all study analyses.

\section{Children's depression inventory}

Children described their current symptoms of depression using the children's depression inventory (CDI) [19]. The CDI is a 27-item questionnaire with a three-point response scale. This scale yields a total $T$ score, indicating the severity of depressed mood, as well as several factor scores. Only the CDI-total age/gender corrected $T$ score was used in the present study. Higher scores suggest more depressive symptoms. Acceptable psychometrics have been reported for the CDI [19].

\section{Child behavior checklist}

CBCL [5] is a 118-item parent report scale that includes broadband subscales of internalizing and externalizing symptomatology, as well as specific scales developed to provide information on a broad range of competencies and behavior problems in preschoolers, school-age children, and adolescents. The items are empirically derived based on their ability to discriminate between clinically referred and clinically healthy samples. Solid psychometric properties have been demonstrated [5]. In addition to subscales that contribute to the internalizing (withdrawal, somatic complaints, and anxious/depressed) and externalizing (delinquent behavior and aggressive behavior), we examined the social problems, thought problems, and attention problems subscales. Age and gender-based $T$ scores (mean 50; SD 10) are reported and used in all study analyses.

\section{Child obsessive compulsive impact scale, revised-parent report}

The child obsessive compulsive impact scale, revisedparent report (COIS-R-P) [37] is a 33-item self-report questionnaire designed to assess the impact of OCD symptoms on the psychosocial functioning of clinic-referred children and adolescents in the home, social, and academic environment. Parents are asked to rate how much difficulty their child has had completing each activity due to his or her anxiety symptoms during the last month. Each item is scored on a 4-point Likert-type scale ("0" not at all, " 1 " just a little, " 2 " pretty much, " 3 " very much). A total score is generated with higher scores suggesting greater impairment. Excellent internal consistency was found in the present sample for the COIS-R-P $(\alpha=0.91)$ [7].

\section{Family environment scale}

The family environment scale (FES) is a 90-item selfreport measure designed to assess ten domains of family social functioning. Internal consistency on the FES in the present sample was $\alpha=0.74$. Parents of children with OCD completed the FES. The following two domains were used in analyses of the present study: cohesion, or the degree to which family members support each other; and conflict, a measure of overt discord among family members [31].

\section{Global axis of functioning}

Global axis of functioning (GAF) [6] is numeric scale (0-100) used by mental health professionals to rate overall social, occupational and psychological functioning.

Procedure

The measures used in the present study were collected as part of a larger assessment battery administered to all 
children seeking clinical services. Informed consent to use these data for research purposes was obtained from parents (and assent from children) prior to the onset of the assessment and the study was approved by the University Institutional Review Board. Children and parents were interviewed separately by the same interviewer who then integrated this information to determine the ADIS-IV diagnostic profile. Evaluations were administered as part of the baseline treatment study visit by doctoral-level psychologists or doctoral students in clinical psychology. All doctoral students received in-depth training from the clinic director or associate director based on the guidelines specified by the interview developers, including co-rating to both videotaped and live interviews. A licensed clinical psychologist (JP or RLB) supervised all clinical evaluations. Following administration of the ADIS-IV/KSADS supplement in a therapy room, children and parents completed self-report measures in a private room within the clinic with assistance from a research assistant as needed. Evaluations were completed in one visit. When two parents were present they both were included in the ADIS-IV parent interview and they decided who was to fill out the parent report documents with instructions to have it filled out by the parent who spends the most time with the child and may therefore best know how to respond.

\section{Group formation}

For purposes of the present study, participants were divided into three groups based on their diagnostic status as generated by the ADIS-IV. The OCD group consisted of youth with OCD as a primary disorder and no comorbid anxiety or externalizing diagnoses. The OCD + anxiety disorder group consisted of youth with (1) a primary diagnosis of OCD as well as (2) at least one of the following comorbid anxiety disorders: generalized anxiety disorder (GAD), social phobia, separation anxiety disorder (SAD), specific phobia, panic disorder (PD), post-traumatic stress disorder (PTSD) and (3) no comorbid externalizing diagnoses. The OCD + externalizing disorder group consisted of those youth with (1) a primary diagnosis of OCD as well as (2) comorbid ADHD (any type), ODD, and/or CD and (3) none of the non-OCD anxiety diagnoses listed above.

\section{Data analyses}

One-way ANOVA and relevant post hoc analyses (Bonferroni) were used to assess differences across study groups in terms of age, age of OCD onset, diagnostic severity, functional status, internalizing and externalizing symptomatology, and family environment. The Bonferroni post hoc analyses calculates a new pairwise alpha to keep the familywise $\alpha$ value at 0.05 (or another specified value).
Potential group differences in terms of gender and the prevalence of comorbid tic and depressive disorders were examined using $\chi^{2}$.

\section{Results}

Thirty-three percent of the sample met criteria for a secondary anxiety disorder (OCD $+\mathrm{ANX} ; N=72$ ) and $13 \%$ for an externalizing disorder (OCD + EXT; $N=28$ ). Fifty-one percent of the sample met criteria for OCD but no other anxiety disorders nor externalizing disorders (OCD; $N=109$ ). The remaining $3 \%$ met criteria for OCD and both an additional anxiety disorder and an externalizing disorder. These individuals $(N=6)$ were omitted from study analyses due to insufficient sample size for statistical comparison. Across the remaining 209 youngsters, 12\% met criteria for a secondary tic disorder, and $8 \%$ for depressive disorders.

The breakdown of comorbid disorders within the OCD + anxiety and the OCD + externalizing groups was as follows: GAD (59\%), social phobia (31\%), SAD (23\%), specific phobia (11\%), PD (2\%) and PTSD (1\%). The breakdown of externalizing disorders includes: ADHDany type (77\%), ODD (39\%), and no participants in the sample met criteria for a diagnosis of CD (see Table 1).

The groups did not differ in terms of gender $\left[\chi^{2}(3)=3.1\right.$, $P=0.37]$ or age $[F(2,207)=2.6, P=0.07]$. One-way ANOVA and Bonferroni post hoc analyses revealed ADISIV CSR ratings for OCD to be significantly higher for youth in the OCD + ANX group $[F(2,206)=8.7, P<0.001]$ compared to both the OCD group and the OCD + EXT group (see Table 2). GAF ratings were significantly lower for the OCD $+\operatorname{EXT}[F(2,197)=3.0, P<0.05]$ as compared to the OCD group, but not the OCD + ANX. There was no difference in age of OCD onset across groups $[F(2$, 204) $=1.05, P=0.36]$.

Parent $[F(2,174)=7.48, P<0.001]$ reports suggested greater OCD-specific functional impairment on the COISR-P for the OCD + EXT group compared to the other two groups. In terms of family functioning, parents of OCD + EXT youth reported less cohesion compared to families of youngsters in the OCD group, but not OCD + ANX group $[F(2,144)=3.5, P<0.05]$. Interestingly, families with children in the OCD + ANX group reported higher levels of family conflict in comparison to the OCD + EXT but not OCD groups $[F(2,144)=5.0$, $P<0.01]$.

Children in the OCD + ANX reported significantly higher total depression $T$ scores on the CDI $[F(2,171)=$ 4.4, $P<0.01]$ and higher MASC total scores $[F(2,144)=$ 9.9, $P<0.001]$ in comparison with the OCD group, but not in comparison with the OCD + EXT group. 
Table 1 Breakdown of comorbid diagnoses for the OCD + ANXIETY and OCD + externalizing disorders groups

PTSD Post-traumatic stress disorder

Table 2 Relationships between clinical and functional measures to the OCD study groups

OCD only, child met diagnostic criteria for OCD but not ANX or EXT; OCD + ANX, child met diagnostic criteria for OCD and at least one anxiety disorders; OCD + EXT, child met diagnostic criteria for OCD and an externalizing disorder; COIS-R, child obsessive compulsive impact scale, revised; CDI, children's depression inventory; MASC, multidimensional anxiety scale for children; FES, family environmental scale; CBCL, child behavior checklist

Values sharing superscripts are significantly different from each other at $P<0.05$ level (at minimal, after Bonferroni correction)

\begin{tabular}{llrl}
\hline Study group & Secondary diagnosis & $N \quad \%$ of group \\
\hline OCD + anxiety & & 72 & \\
& Generalized anxiety disorder & 43 & 59 \\
& Social phobia & 22 & 31 \\
& Separation anxiety disorder & 17 & 23 \\
& Specific phobia & 8 & 11 \\
& Panic disorder & 1 & 2 \\
& PTSD & 1 & 1 \\
OCD + externalizing & 28 & \\
& Attention deficit hyperactivity disorder-combined type & 16 & 58 \\
& Attention deficit hyperactivity disorder-inattentive type & 5 & 16 \\
& Attention deficit hyperactivity disorder-hyperactive/impulsive & 1 & 3 \\
& type & & \\
& Oppositional defiant disorder & 11 & 39 \\
\hline
\end{tabular}

\begin{tabular}{lcll}
\hline & OCD (mean, SD) & OCD + ANX (mean, SD) & OCD + EXT (mean, SD) \\
\hline AGE & $11.9(3.1)$ & $12.2(3.0)$ & $10.6(3.1)$ \\
ADIS OCD CSR & $5.2(.88)^{\mathrm{a}}$ & $5.7(.70)^{\mathrm{a}, \mathrm{b}}$ & $5.2(.73)^{\mathrm{b}}$ \\
GAF & $54.0(6.9)^{\mathrm{a}}$ & $52.7(4.9)$ & $50.8(6.6)^{\mathrm{a}}$ \\
COISR & & & \\
Parent total & $27.4(19.4)^{\mathrm{a}}$ & $27.1(15.5)^{\mathrm{b}}$ & $39.0(17.6)^{\mathrm{a}, \mathrm{b}}$ \\
Child total & $17.2(16.7)^{\mathrm{a}}$ & $22.3(17.0)^{\mathrm{b}}$ & $27.3(19.7)^{\mathrm{a}, \mathrm{b}}$ \\
CDI total & $48.5(10.3)^{\mathrm{a}}$ & $53.4(11.0)^{\mathrm{a}}$ & $54.2(13.1)$ \\
MASC total & $47.2(15.9)^{\mathrm{a}}$ & $62.6(13.3)^{\mathrm{a}}$ & $56.5(16.3)$ \\
FES & & & $5.1(1.9)$ \\
Cohesion & $4.9(1.7)$ & $4.5(1.9)$ & $4.2(2.5)^{\mathrm{a}}$ \\
Conflict & $5.3(2.5)$ & $6.2(2.2)^{\mathrm{a}}$ & \\
CBCL & & & $65.3(8.4)$ \\
Internalizing behavior & $63.9(9.2)^{\mathrm{a}}$ & $68.0(8.8)^{\mathrm{a}}$ & $60.4(8.0)$ \\
$\quad$ Withdrawal & $59.9(9.2)$ & $60.1(11.6)$ & $61.5(7.8)$ \\
Somatic complaints & $58.8(7.8)^{\mathrm{a}}$ & $63.5(10.1)^{\mathrm{a}}$ & $66.3(9.9)$ \\
Anxiety/depression & $66.5(9.6)^{\mathrm{a}}$ & $70.1(8.7)^{\mathrm{a}}$ & $63.6(9.3)^{\mathrm{a}, \mathrm{b}}$ \\
Externalizing behavior & $52.9(10.0)^{\mathrm{a}}$ & $54.0(8.5)^{\mathrm{b}}$ & $60.2(8.9)^{\mathrm{a}, \mathrm{b}}$ \\
Delinquent behavior & $54.3(6.3)^{\mathrm{a}}$ & $53.6(5.6)^{\mathrm{b}}$ & $65.8(10.1)^{\mathrm{a}}, \mathrm{b}$ \\
Aggression & $56.1(7.4)^{\mathrm{a}}$ & $56.7(7.4)^{\mathrm{b}}$ & $64.4(9.0)^{\mathrm{b}}$ \\
Social problems & $56.0(7.3)^{\mathrm{a}, \mathrm{b}}$ & $59.8(9.1)^{\mathrm{a}}$ & $73.0(8.0)$ \\
Thought problems & $72.9(7.6)$ & $73.5(6.9)$ & $70.3(7.8)^{\mathrm{a}, \mathrm{b}}$ \\
Attention problems & $61.5(10.3)^{\mathrm{a}}$ & $62.8(7.7)^{\mathrm{b}}$ & \\
\hline & & &
\end{tabular}

As expected, the OCD + EXT group had significantly higher externalizing $T$ scores on the CBCL $[F(2,181)=$ 12.3, $P<0.001]$ compared to the other two groups. Conversely, the OCD + ANX group had significantly higher $T$ scores on the internalizing scale of the CBCL $[F(2,181)=3.8, P<0.05]$ in comparison to the OCD, but not OCD + EXT, group. Children with OCD + EXT were also rated as having significantly more problems than the other two groups on the following scales: attention problems $[F(2,181)=8.5, P<0.001]$, and delinquent behavior $[F(2,181)=9.2, \quad P<0.001]$ and aggressive behavior $[F(2,181)=14.6, P<0.001]$. Children in the OCD group had fewer social problems $[F(1,181)=11.5$, $P<0.001]$ than either comorbid group. Finally, the OCD + ANX group received higher scores on the somatic complaints $[F(1,181)=5.8, \quad P<0.01]$ and anxiety/ depression $[F(1,181)=3.9, P<0.05]$ subscales compared to the OCD, but not the OCD + EXT group. 
As predicted, children with OCD only (14.7\%) $\left[\chi^{2}(1)=5.1, \quad P=0.02\right] \quad$ and $\quad$ OCD + EXT $\quad(25 \%)$ $\left[\chi^{2}(1)=9.7, P<0.01\right]$ were more likely to have a tic disorder than children with OCD + ANX (4.2\%). However, the OCD and OCD + EXT groups did not significantly differ on this variable $\left[\chi^{2}(1)=1.7, P=0.15\right]$. No significant group differences were found for the occurrence of depressive disorders [OCD (10\%) and OCD + ANX $\left.(11 \%) \chi^{2}(1)=0.05, P=0.886\right)$; OCD and OCD + EXT $\left.(10.7 \%) \quad \chi^{2}(1)=0.01, \quad P=0.92\right) ; \quad$ OCD + ANX and OCD + EXT, $\left.\chi^{2}(1)=0.01, P=0.96\right)$.

Given the significant difference in OCD severity between the OCD + ANX and other groups, the above ANOVAs were re-run controlling for this variable. These analyses yielded three changes from the original findings. Previously significant differences between the OCD and OCD + ANX groups on the CDI Total $[F(2,172)=2.8$, $P=0.06], \quad$ CBCL internalizing $[F(2,180)=2.7, \quad P=$ $0.07]$, and CBCL anxiety/depression $[F(2,180)=2.8, P=$ $0.07]$ scores were only significant at the trend level.

\section{Discussion}

Childhood OCD is a heterogeneous illness with comorbidity found to be the norm rather than the exception [17, 22, 29, 44]. Comorbid psychopathology may also have implications for the clinical treatment of childhood OCD $[27,46]$ and consequently, a better understanding of the impact of comorbidity on OCD in children and adolescents is warranted.

The present study examined the demographic, psychiatric, and functional correlates of both internalizing (anxiety) and externalizing (ADHD and ODD) comorbidity in a large group of children and adolescents $(N=209)$ with a primary DSM-IV diagnosis of OCD and found higher levels of functional impairment and OCD diagnostic severity in the comorbid as opposed to non-comorbid youngsters. More specifically, as compared to uncomplicated OCD, the present study found greater OCD severity in children with co-occurring anxiety disorder and lower overall functioning among children with comorbid externalizing disorders.

In addition, children with comorbid externalizing disorders had more behavioral, social and attentional problems as indicated by the CBCL than children with comorbid anxiety or no anxiety or externalizing comorbidities. This is consistent with Geller et al.'s [12] findings comparing youth with OCD and ADHD to those with OCD and not ADHD. Ivarsson et al. [17] found elevated levels on these subscales in youth with OCD in comparison to a normative sample. The current data suggests that some of these elevations may be mediated by diagnostic comorbidities; however, behavioral and attentional problems may also be driven by OCD-related anxiety. For example, if a child is experiencing anxiety due to an OCD obsession and is not accommodated in the way his or her OCD seems to demand, he or she may act out behaviorally [35]. Similarly, attention difficulties can be a result of both obsessive preoccupation and OCDrelated worry/anxiety as well as potential clinical or subclinical comorbidities such as ADHD. Interestingly, children with OCD and comorbid anxiety had greater levels of somatic complaints, anxiety/depression, and overall internalizing symptoms on the CBCL than those with OCD alone but not those with OCD plus comorbid externalizing disorder. However, this difference largely disappeared when controlling for OCD severity. Although limited by the cross-sectional methodology, these findings suggest that increased depressive symptoms associated with comorbid anxiety may be more closely related to increased OCD severity than comorbid anxiety. As a result, assessment and consideration of both OCD symptom severity and comorbidity may enable a better understanding of ways to improve the clinical management of children with OCD.

In addition, youth with comorbid externalizing disorders had greater OCD-specific functional impairment (school, social, and familial) in comparison to the other two groups. This may not be surprising given that child anxiety has a history of being viewed as less obviously problematic than the externalizing behavior disorders [52] and that the more disruptive nature of these disorders may create more notable intrusion into daily activities.

The presence of comorbid externalizing disorder was also associated with lower levels of family cohesion. However, children with comorbid anxiety disorders reported higher levels of family conflict compared to the OCD plus externalizing group. Although this finding is consistent with previous reports of higher levels of family conflict among anxious youth [16], clearly the mechanisms underlying the relationship between comorbid disorder and family environment warrant further study.

Consistent with prior research documenting the relationship between OCD, ADHD, and tic disorders [20, 33], the highest rate of comorbid tic disorder was found in the OCD plus externalizing group. To our knowledge, the relatively low rate of tic disorders among the OCD + ANX group has not been reported before and requires further study. However, this finding may be related to the clinical distinction between predominantly anxiety-based OCD symptoms and the sensory/tactile (e.g., "just right phenomenon") symptom presentation previously reported to characterize individuals with comorbid OCD and tics [14, 25]. 
Even though comorbid anxiety disorder was associated with higher rates of depressive symptoms on the CDI, the prevalence of DSM-IV depressive disorder did not differ across the three groups. The reasons for this are not immediately clear, although it may be that CDI scores reflect increased levels of general distress in the OCD + ANX group that were not sufficiently elevated nor specific enough to warrant a formal DSM-IV-TR depressive-spectrum diagnosis. Alternately, the rate of depression in our sample was relatively low, likely reflecting the younger age and focus on current, not lifetime, diagnoses.

Despite the intuitive nature of many of our findings, the existing literature lacks sufficient documentation of the impact of co-occurring anxiety and externalizing disorders on childhood OCD. Overall, and unlike comorbid tic disorders [14, 47], the presence of comorbid anxiety and externalizing psychopathology (among the most common co-occurring conditions in youngsters with OCD) is associated with greater symptom severity and functional and family impairment. Recent documentation of the negative impact comorbid symptomatology can have on response of OCD to both medication and cognitive-behavioral treatment $[27,46]$ further underscores the importance of a better understanding of the relationship of OCD characteristics and associated disorders.

\section{Limitations and future directions}

Although the present study was characterized by a number of design strengths, including a relatively large sample and a comprehensive and standardized assessment battery, the findings reported here must be evaluated in light of certain methodological limitations. First, the sample was not large enough to examine the relationship of our dependent variables to specific anxiety or disruptive behavior disorders, including conduct disorder. In addition, the number of OCD youngsters with both anxiety and externalizing diagnoses was too small to allow for examination of the additive effects of these disorders. Insufficient prevalence also precluded formation of study groups based on other patterns of comorbidity, such as tic or depressive disorder. Finally, relatively low internal consistency ratings on the included dimensions of the FES makes interpretation less robust. Of note, our data are based on clinic referrals and may not generalize to more naturalistic samples. We were also not able to include an assessment of parental diagnostic status or psychopathology.

In addition to more detailed cross-sectional evaluations of comorbidity patterns, a longitudinal evaluation of comorbidity development is warranted. Longitudinal studies will be needed to identify the mechanisms underlying the relationship between comorbidity and the illness severity and functional impacts identified in the present study. Long-term research will also be important for providing insight into the developmental course of comorbid psychopathology, including risk and protective factors (e.g., early treatment, family psychopathology, domestic stressors, cognitive functioning, coping style, and social support). At this time, it remains unclear if anxiety and externalizing disorders are comorbid (implying similar causation) or co-occurring pathologies. Importantly, initial reports regarding the impact of comorbid symptoms, particularly disruptive behavior disorder, depressive disorder, and attention deficit hyperactivity disorder, on response to treatment $[27,46]$ require replication and extension.

Acknowledgments This research was supported, in part, by NIMH grant R01 MH58459 (J. Piacentini, P.I.).

Open Access This article is distributed under the terms of the Creative Commons Attribution Noncommercial License which permits any noncommercial use, distribution, and reproduction in any medium, provided the original author(s) and source are credited.

\section{References}

1. Abramowitz JS (2004) Treatment of obsessive compulsive disorder in patients who have comorbid depression. J Clin Psychol 60:1133-1141

2. Abramowitz JS, Foa EB (1998) Worries and obsessions in individuals with obsessive-compulsive disorder with and without comorbid generalized anxiety disorder. Behav Res Ther 36:695700

3. Abramowitz JS, Foa EB (2000) Does major depressive disorder influence outcome of exposure and response prevention for OCD? Behav Ther 31:795-800

4. Abramowitz JS, Storch EA, Keeley M, Cordell E (2007) Obsessive- compulsive disorder with comorbid major depression: what is the role of cognitive factors? Behav Res Ther 45:22572267

5. Achenbach TM (1994) Child behavior checklist and related instruments. In: Maruish ME (ed) The use of psychological testing for treatment planning and outcome assessment. Lawrence Erlbaum Associates, Hillsdale, pp 517-549

6. American Psychiatric Association (2000) Diagnostic and statistical manual of mental disorders (DSM-IV-TR), 4th edn (text revision). American Psychiatric Association, Washington, DC

7. Cronbach LJ (1951) Coefficient alpha and the internal structure of tests. Psychometrika 16:297-334

8. Douglas WW, Piacentini J, Himle MB, Chang S (2005) Premonitory urge for tics scale (PUTS): initial psychometric results and examination of the premonitory urge phenomenon in youths with tic disorders. J Dev Behav Pediatr 26:397-403

9. Franco X, Saavedra LM, Silverman WK (2007) External validation of comorbid patterns of anxiety disorders in children and adolescents. J Anxiety Disord 21:717-729

10. Geller DA (2006) Obsessive-compulsive and spectrum disorders in children and adolescents. Psychiatr Clin N Am 29:353-370

11. Geller DA, Biederman J, Faraone S, Agranat A, Cradock K, Hagermoser L et al (2001) Developmental aspects of obsessive compulsive disorder: findings in children, adolescents, and adults. J Nerv Ment Dis 189:471-477 
12. Geller DA, Biederman J, Faraone S, Spencer T, Doyle R, Mullin B et al (2004) Re-examining comorbidity of obsessive compulsive and attention-deficit hyperactivity disorder using an empirically derived taxonomy. Eur Child Adolesc Psychiatry 13:83-91

13. Geller DA, Biederman J, Griffin S, Jones J, Lefkowitz TR (1996) Comorbidity of juvenile obsessive-compulsive disorder with disruptive behavior disorders. J Am Acad Child Adolesc Psychiatry $35: 1637-1646$

14. Hanna GL, Piacentini J, Cantwell DP, Fischer DJ, Himle JA, Van Etten M (2002) Obsessive-compulsive disorder with and without tics in a clinical sample of children and adolescents. Depress Anxiety 16:59-63

15. Hanna GL, Yuwiler A, Coates JK (1995) Whole blood serotonin and disruptive behaviors in juvenile obsessive-compulsive disorder. J Am Acad Child Adolesc Psychiatry 34:28-35

16. Heng-Fen LI, Su-Xia C, Yong Z (2006) Family environment and cognitive function of middle school students with depression and anxiety. Chin Ment Health J 20(9):582-585

17. Ivarsson T, Melin K, Wallin L (2008) Categorical and dimensional aspects of co-morbidity in obsessive-compulsive disorder (OCD). Eur Child Adolesc Psychiatry 17:20-31

18. Kaufman J, Birmaher B, Brent D, Rao U, Flynn C, Moreci P, Williamson D, Ryan N (1997) Schedule for affective disorders and schizophrenia for school-age children-present and lifetime version (K-SADS-PL): initial reliability and validity data. J Am Acad Child Adolesc Psychiatry 36:980-988

19. Kovacs M (1985) The children's depression, inventory (CDI). Psychopharmacol Bull 21:995-998

20. Leckman JF, Goodman WK, Anderson GM, Riddle MA, Chappell PB, Swiggan-Hardin MT (1995) Cerebrospinal fluid biogenic amines in obsessive-compulsive disorder, Tourette's syndrome, and healthy controls. Neuropsychopharmacology 12:73-86

21. Lewin AB, Piacentini J (2009) Obsessive-compulsive disorder in children. In: Sadock BJ, Sadock VA, Ruiz P (eds) Kaplan and Sadock's comprehensive textbook of psychiatry, 9th edn. Lippincott Williams \& Wilkins, a Wolters Kluwer Business, Philadelphia, pp 3671-3678

22. Lewin AB, Storch EA, Adkins JW, Merlo LJ, Murphy TK, Goodman WK et al (2005) Update and review on pediatric obsessive-compulsive disorder. Psychiatr Ann 35:745-751

23. Lewin AB, Storch EA, Geffken GR, Goodman WK, Murphy TK (2006) A neuropsychiatric review of pediatric obsessive-compulsive disorder: etiology and efficacious treatments. Neuropsychiatr Dis Treat 2:21-31

24. Lewin AB, Storch EA, Merlo LJ, Adkins JW, Murphy TK, Geffken GR (2006) Intensive cognitive behavioral therapy for pediatric obsessive compulsive disorder: a treatment protocol for mental health providers. Psychol Serv 2:91-104

25. Mansueto CS, Keuler DJ (2005) Tic or compulsion? It's Tourettic OCD. Behav Modif 29:784-799

26. March JS (1995) Cognitive-behavioral psychotherapy for children and adolescents with OCD: a review and recommendations for treatment. J Am Acad Child Adolesc Psychiatry 34:7-18

27. March JS, Franklin ME, Leonard H, Garcia A, Moore P, Freeman J et al (2007) Tics moderate treatment outcome with sertraline but not cognitive-behavior therapy in pediatric obsessive-compulsive disorder. Biol Psychiatry 61:344-347

28. March JS, Parker JD, Sullivan K, Stallings P, Conners CK (1997) The multidimensional anxiety scale for children (MASC): factor structure, reliability, and validity. J Am Acad Child Adolesc Psychiatry 36:554-565

29. Masi G, Millepiedi S, Mucci M, Bertini N, Milantoni L, Arcangeli F (2005) A naturalistic study of referred children and adolescents with obsessive-compulsive disorder. J Am Acad Child Adolesc Psychiatry 44:673-681
30. Moore PS, Mariaskin A, March J, Franklin ME (2007) Obsessive compulsive disorder in children and adolescents: diagnosis, comorbidity, and developmental factors. In: Storch EA, Geffken GR, Murphy TK (eds) Handbook of child and adolescent obsessive-compulsive disorder. Lawrence Erlbaum Associates Publishers, Mahwah, pp 17-45

31. Moos R, Moos B (1994) Family environmental scale manual: development, applications, research, 3rd edn. Consulting Psychologist Press, Palo Alto

32. Nestadt G, Samuels J, Riddle M, Bienvenu O J III, Liang KY, LaBuda M et al (2000) A family study of obsessive-compulsive disorder. Arch Gen Psychiatry 57:358-363

33. Pauls DL, Alsobrook JP, Goodman W, Rasmussen S, Leckman JF (1995) A family study of obsessive-compulsive disorder. Am J Psychiatry 152:76-84

34. Peris TS, Bergman RL, Asarnow J, Langley A, McCracken J, Piacentini J (2010) Clinical and cognitive correlates of depressive symptoms among youth with obsessive compulsive disorder. J Clin Child Adolesc Psychol (in press)

35. Peris TS, Bergman RL, Langley A, Chang S, McCracken JT, Piacentini J (2008) Correlates of family accommodation of childhood obsessive compulsive disorder: parent, child, and family characteristics. J Am Acad Child Adolesc Psychiatry 47:1173-1181

36. Piacentini J, Bergman RL, Keller M, McCracken J (2003) Functional impairment in children and adolescents with obsessive-compulsive disorder. J Child Adolesc Psychopharmacol 13:61-69

37. Piacentini J, Peris TS, Bergmen RL, Chang S, Jaffer M (2007) Functional impairment in childhood OCD: development and psychometrics properties of the child obsessive-compulsive impact scale-revised (COIS-R). J Clin Child Adolesc Psychol 36:645-653

38. Rasmussen SA, Eisen JL (1992) The epidemiology and clinical features of obsessive compulsive disorder. Psychiatr Clin N Am 15:743-758

39. Reddy YC, Reddy PS, Srinath S, Khanna S, Sheshadri SP, Girimaji SC (2000) Comorbidity in juvenile obsessive-compulsive disorder: a report from India. Can J Psychiatry 45:274-278

40. Riddle MA, Hardin MT, King R, Scahill L, Woolston JL (1990) Fluoxetine treatment of children and adolescents with Tourette's and obsessive compulsive disorders: preliminary clinical experience. J Am Acad Child Adolesc Psychiatry 29:45-48

41. Shugart Y, Samuels J, Willour V, Grados M, Greenberg B, Knowles J, McCracken J, Rauch S, Murphy D, Wang Y, Pinto A, Fyer A, Piacentini J, Pauls D, Cullen B, Page J, Rasmussen S, Bienvenu J, Hoehn-Saric R, Valle D, Liang K, Riddle M, Nestadt J (2006) Evidence for susceptibility loci on chromosomes 3q, 7p, 15q, 6q, and 1q. Mol Psychiatry 11:763-770

42. Silverman WK, Albano AM (1996) The anxiety disorders interview schedule for DSM-IV-child and parent versions. Graywinds Publications, San Antonio

43. Silverman WK, Saavedra LM, Pina AA (2001) Test-retest reliability of anxiety symptoms and diagnoses with the anxiety disorders interview schedule for DSM-IV: child and parent versions. J Am Acad Child Adolesc Psychiatry 40:937-944

44. Snider LA, Swedo SE (2000) Pediatric obsessive-compulsive disorder. JAMA 284:3104-3106

45. Stewart SE, Geller DA, Jenike M, Pauls D, Shaw D, Mullin B, Faraone SV (2004) Long-term outcome of pediatric obsessivecompulsive disorder: a meta-analysis and qualitative review of the literature. Acta Psychiatr Scand 110:4-13

46. Storch EA, Merlo LJ, Larson MJ, Geffken GR, Lehmkuhl HD, Jacob ML, Murphy TK, Goodman WK (2008) The impact of comorbidity on cognitive-behavioral therapy response in 
pediatric obsessive compulsive disorder. J Am Acad Child Adolesc Psychiatry 47(5):583-592

47. Storch EA, Stigge-Kaufman D, Marien WE, Sajid M, Jacob ML, Geffken GR et al (2007) Obsessive-compulsive disorder in youth with and without a chronic tic disorder. Depress Anxiety 25(9):761-767

48. Strauss CC, Last CG, Hersen M, Kazdin AE (1988) Association between anxiety and depression in children and adolescents with anxiety disorders. J Abnorm Child Psychol 16:57-68

49. Swedo SE, Rapoport JL, Leonard H, Lenane M, Cheslow D (1989) Obsessive-compulsive disorder in children and adolescents. Clinical phenomenology of 70 consecutive cases. Arch Gen Psychiatry 46:335-341

50. Tukel R, Polat A, Ozdemir O, Aksut D, Turksoy N (2002) Comorbid conditions in obsessive-compulsive disorder. Compr Psychiatry 43:204-209
51. Valderhaug R, Larsson B, Gotesam G, Piacentini J (2006) An open clinical trial with cognitive behavior therapy administered in outpatient psychiatric clinics to children and adolescents with OCD. Behav Res Ther 45:577-589

52. Vasey MW, Dadds MR (2001) An introduction to the developmental psychopathology of anxiety. In: Vasey MW, Dadds MR (eds) The developmental psychopathology of anxiety. Oxford University Press, Oxford, pp 3-26

53. Wood JJ, Piacentini JC, Bergman RL, McCracken J, Barrios V (2002) Concurrent validity of the anxiety disorders section of the anxiety disorders interview schedule for DSM-IV: child and parent versions. J Clin Child Adolesc Psychol 31:335-342

54. Zohar AH (1999) The epidemiology of obsessive-compulsive disorder in children and adolescents. Child Adolesc Psychiatr Clin N Am 8:445-460 